\title{
Estrutura macro e microscópica das glândulas salivares parótidas em duas espécies de procionídeos: mão-pelada (Procyon cancrivorus, G. Cuvier, 1798) e quati (Nasua nasua, Linnaeus, 1766)
}

\author{
Amilton Cesar dos Santos* \\ Bruno Machado Bertassoli \\ Franceliusa Delys de Oliveira \\ Daniela Moraes de Oliveira \\ Vanessa Cristina de Oliveira \\ Bruno Gomes Vasconcelos \\ Ana Flávia de Carvalho \\ Celina Almeida Furlanetto Mançanares \\ Antônio Chaves Assis Neto \\ Faculdade de Medicina Veterinária e Zootecnia, Departamento de Cirurgia \\ PPG em Anatomia dos Animais Domésticos e Silvestres, Universidade de São Paulo \\ Avenida Professor Dr. Orlando Marques de Paiva, CEP 05508-270, São Paulo - SP, Brasil \\ *Autor para correspondência \\ amiltonsantoss@usp.br
}

Submetido em 07/06/2011

Aceito para publicação em 22/10/2011

\section{Resumo}

O quati (Nasua nasua, Linnaeus, 1766), de hábito diurno, e o mão-pelada (Procyon cancrivorus, G. Cuvier, 1798), de hábito crepuscular e noturno, são espécies de mamíferos terrestres, pertencentes à família dos procionídeos, que são amplamente encontrados no território brasileiro. Para este trabalho foram utilizados três quatis e dois mãos-peladas adultos provenientes do Criatório Científico-Cecrimpas do Centro Universitário da Fundação de Ensino Octávio Bastos (Ibama 02027.003731/04-76) dos quais foram obtidas amostras de tecido das glândulas salivares parótidas coradas em H.E. para microscopia de luz. Constatou-se que a glândula parótida dos quatis e mãos-peladas possui posicionamento semelhante à dos demais carnívoros domésticos, com seus ductos se abrindo no vestíbulo oral, próximo à altura do quarto dente pré-molar superior, e que histologicamente as glândulas parótidas dos quatis e mão-peladas são constituídas por ácinos serosos, assemelhando-se à maioria dos animais domésticos, homens e roedores e diferindo dos resultados encontrados nos cães jovens, cordeiros e outros carnívoros como o furão que possuem ácinos mistos, e de alguns carnívoros, que apresentam ácinos serosos e mucosos. Conclui-se que o fato da constituição serosa dos ácinos das glândulas parótidas dos quatis e mão-peladas se assemelhar pode ser devido ao hábito alimentar onívoro compartilhado pelas duas espécies.

Palavras-chave: Glândula parótida, Mão-pelada, Morfologia, Quati 


\section{Abstract}

Macro and microscopic structure of parotids salivary glands in two species of procyonidae: raccoon (Procyon cancrivorus, G. Cuvier, 1798) and coati (Nasua nasua, Linnaeus, 1766). Coati (Nasua nasua), a diurnal animal, and raccoon (Procyon cancrivorus), a crepuscular and nocturnal one, are species of terrestrial mammals, belonging to the procyonidae family, that are widely found in the Brazilian territory. For this work were used three adult coatis and two adult raccoons adults from the Scientific Breeding-Cecrimpas of Centro Universitario da Fundacão de Ensino Octávio Bastos (Ibama 02027.003731/04-76) were used, from which tissue samples of parotid salivary glands were obtained and stained H.E. for light microscopy. It was found that the parotid glands of coatis and raccoons has a positioning similar to that of the other domestic carnivores, opening their ducts within the oral cavity close to the fourth upper premolar tooth, as well as that histologically the parotid glands of coatis and raccoons are formed by serous acini, similarly to most of the domestic animals, humans beings and rodents, and differently from the results found in young dogs, lambs and some carnivores such as the ferret which have mixed acini and other ones which have serous. One concludes that the similarity in serous constitution of the parotid glands of coatis and raccoons might be due to the omnivorous feeding habit shared by these two species.

Key words: Coati, Morphology, Parotid gland, Raccoon

\section{Introdução}

O quati (Nasua Nasua, Linnaeus, 1758) e o mãopelada (Procyon cancrivorus, G. Cuvier, 1798) são animais que pertencem ao Filo Chordata, à Classe Mammalia, à Ordem Carnívora e à Família Procyonidae, que é dividida em duas subfamílias: Procioninae e Ailurinae. Os representantes da subfamília Procioninae são chamados de procionídeos e são representados por quatro gêneros na América do Sul: Procyon, Nasua, Potos, Bassaricyon (SANTOS et al., 2010a).

Os Procionídeos possuem porte médio, pernas curtas, e pelagem densa. São plantígrados, possuem cinco dedos em cada um dos membros, e, como suas mãos são móveis possuem habilidade para cavar e são ótimos escaladores. São onívoros e se alimentam de frutos, pequenos vertebrados, crustáceos, insetos, néctar, ovos e legumes. Nessa família, existem espécies arborícolas e terrestres, porém todas as espécies utilizam as árvores, para repousar, buscar alimentos, fugir do perigo ou nidificar (SANTOS et al., 2010a).

O quati é um procionídeo de hábito diurno que pode ser facilmente identificado pelo focinho longo em forma de trombeta que se destaca diante dos olhos e orelhas pequenas. Possuem caninos longos e ao redor dos olhos observam-se manchas claras. Sua cauda é longa, vistosa e ornada de anéis claros e escuros de pelagem densa (BEISIEGEL, 2001; SANTOS et al., 2010a).
O mão-pelada é um animal de hábito noturno e crepuscular, de cauda longa amarelada com a ponta negra e ornada com 5 a 10 largos anéis escuros e amarelados. Uma característica marcante é a máscara negra ao redor dos olhos, que se destaca na face esbranquiçada. A região das mãos é desprovida de pelos, característica que lhe conferiu o nome popular pelo qual é conhecido no Brasil como mão-pelada (LIMA et al., 2010).

Todos os tetrápodes não aquáticos precisam das secreções mucosas e serosas das glândulas salivares para lubrificar o alimento seco. Tais glândulas exibem um desenvolvimento gradual nas diferentes classes de vertebrados. Aparecem nos anfíbios, desenvolvemse muito em répteis e aves e atingem o máximo do desenvolvimento nos mamíferos (ORR, 1986; GEORGE et al., 1998).

Sua secreção compõe a saliva, que tem a função de: umedecer o epitélio da mucosa e os alimentos; facilitar a mastigação; colaborar no ajuste do $\mathrm{pH}$ do trato digestivo cranial; colaborar na dissolução e degustação dos alimentos, iniciando a digestão limitada dos carboidratos (GEORGE et al., 1998), além de possuir ação antimicrobiana (SAMUELSON, 2007).

Orr (1986) descreveu que evolutivamente alguns mamíferos adquiriram adaptações para utilizarem a salivação como forma de auxiliar o sistema de termorregulação corpóreo, assim enquanto alguns 
animais arfam (respiram com a boca aberta) para evaporação salivar outros esfregam a saliva em seu corpo quando estão sob severa pressão térmica.

A saliva é formada por proteínas, glicoproteínas, eletrólitos e água e está sob o controle reflexo dos centros salivares encefálicos (parassimpático) e medulares (simpático) do sistema nervoso autônomo (BANKS, 1991), sendo inervadas pelos nervos cranianos VII, IX e X (SAMUELSON, 2007).

Algumas enzimas presentes na saliva como a amilase e lipase iniciam o processo digestivo, enquanto outras enzimas como a lactoperoxidase atuam como agentes antimicrobianos, secretando imunoglobulina A (IgA), lisozima e lactoferrina (SAMUELSON, 2007).

As glândulas salivares podem ser divididas em: menores, que se situam mucosa da língua, bochecha, lábios, palato e cavidade oral e maiores, compostas pelas glândulas parótida, mandibular e sublingual, além da zigomática (carnívoros) e molar (gatos) (BANKS, 1991; VIEIRA et al., 2001; SAMUELSON, 2007; SANTOS et al., 2010b).

A glândula parótida é assim chamada pela sua proximidade à orelha (DYCE et al., 2010). Ela está situada essencialmente no espaço caudal ao ramo da mandíbula, onde está firmemente aderida à cartilagem auricular (MOSCOVICI, 2009).

$\mathrm{Na}$ maioria das espécies a glândula parótida possui ácinos serosos, porém em alguns carnívoros sua constituição histológica é mista (ácinos serocomucosos) (DYCE et al., 2010). De acordo com Banks (1991), geralmente a parótida é uma glândula serosa em todos os animais domésticos, homens, roedores adultos e carnívoros, e poucas células mucosas são encontradas, enquanto em cães jovens e cordeiros ela pode ser mista.

O conhecimento da localização exata e de possíveis alterações da abertura oral do ducto excretor das glândulas salivares é de grande importância, perante o desenvolvimento do uso de técnicas mais acuradas na detecção de processos patológicos, desde traumáticos, até tumorais da referida glândula ou de suas vias de escoamento (SANTOS; LIMA, 2001; SANTOS et al., 2010b).
Os estudos a respeito de animais silvestres vêm crescendo dia a dia, e com este interesse necessitase de mais informações sobre sua morfo-fisiologia, comportamento e outros aspectos importantes para sua sobrevivência (SANTOS et al., 2010a).

Dessa forma, essa pesquisa tem por objetivo, descrever a morfologia das glândulas salivares parótidas dos quatis e mãos-peladas, comparando sua arquitetura entre si e com a de outras espécies descritas na literatura para servir de auxílio em futuros tratamentos clínicos dessas espécies, bem como servir de referência para futuros trabalhos com outras espécies.

\section{Material e Métodos}

Para esta pesquisa foram utilizados dois quatis machos e uma fêmea e dois exemplares de mão-pelada, ambos machos e adultos provenientes do CECRIMPAS (IBAMA n02027.002322/98-99), com protocolo de bioética 01.2011 do Centro Universitário Fundação de Ensino Octávio Bastos.

Estes animais foram eutanasiados em outubro de 2009 por médicos veterinários desta instituição para utilização em outras pesquisas anteriores a esta, portanto não houve sacrifício de vidas para esta pesquisa. Estes animais já estavam fixados em solução de formaldeído a $10 \%$.

Esta pesquisa foi realizada utilizando os laboratórios de Morfologia Animal do Centro Universitário da Fundação de Ensino Octávio Bastos, na cidade de São João da BOA VISTA - SP, e Laboratório de Histologia e Embriologia da Faculdade de Medicina Veterinária e Zootecnia da Universidade de São Paulo.

Para a análise macroscópica, as glândulas parótidas foram dissecadas e fotografadas "in situ". Em seguida com o auxílio, de uma pinça e bisturi, foram extraídas as glândulas parótidas, que foram armazenadas em frascos contendo álcool $70 \%$. As amostras foram desidratadas em concentrações crescentes de etanol (60\% a 100\%) e diafanizadas em xilol, para posterior inclusão em parafina Histosec $\square$-MERCK (BEHMER, 1976; TOLOSA et al., 2003). Foram obtidos cortes dos blocos de parafina com $5 \mu \mathrm{m}$ de espessura, cortados em micrótomo Leica RM 
2155, os quais foram corados por HE (Hematoxilina/ Eosina). Em seguida, as lâminas foram montadas com Entelan e lamínulas para posterior observação da morfologia celular. A fotodocumentação microscópica foi realizada com auxílio de fotomicroscópio Leica DM 2000.

A nomenclatura utilizada foi referida conforme International Commitee on Veterinary Gross Anatomical Nomenclature (2005).

\section{Resultados e Discussão}

A glândula parótida, do quati e do mão-pelada, se assemelha à descrição de Greco et al. (2008), nos coelhos, e de Schaller (1999), nos demais carnívoros, onde está localizada caudalmente ao ramo da mandíbula, desde a base do pavilhão auricular, onde se encontra extremamente aderida, até o ângulo da mandíbula (MENDONÇA et al., 2004).

Em sua extremidade ventral, as glândulas parótidas do quati e do mão-pelada, cobrem lateralmente a glândula mandibular e no seu terço dorsal, cobrem a origem aparente do nervo facial, assemelhando-se à descrição de Schaller (1999), nos carnívoros, e de Greco et al. (2008), nos coelhos.

Sua extremidade dorsal é larga e está dividida em duas partes por um profundo sulco que recebe a base da orelha nos quatis e mão-peladas, assim como nos tatus (Zaedyus pickiy) descrito por Estecondo et al. (2005).

A glândula parótida no quati tem formato de "U", enquanto a do mão-pelada tem formato de "Y", devido a suas duas extremidades dorsais que acompanham o formato da cartilagem auricular (Figuras 1A; 2A; 2B). Apresentam-se de tamanho proporcionalmente maior quando comparadas ao cão e gato, nos quais se apresenta pequena e irregularmente triangular (DONE et al., 2002). Difere ainda dos coelhos nos quais ela apresenta-se em formato de halteres, e em alguns casos em formato de pêra (GRECO et al., 2008).

O ducto parotídeo do quati e mão-pelada deixa a glândula parótida, na parte ventral da margem rostral, e cruza o músculo masseter, acompanhando ventralmente os ramos bucais do nervo facial (Figuras 1A; 1B; 2A; 2B), parecido com a posição encontrada nos cães por
Mendonça et al. (2004) e nos coelhos por Greco et al. (2008), porém, diferente do resultado encontrado no gambá (Didelphis sp.) onde o ducto parotídeo entra no espaço entre o músculo digástrico e masseter (MARTUCCI et al., 2004).

No quati e no mão-pelada, o ducto parotídeo se abre no vestíbulo oral, próximo da comissura labial e do quarto dente pré-molar superior, a exemplo do encontrado nos cães por Mendonça et al. (2004).

Nos cães, gatos e humanos podem ser encontradas ainda pequenas glândulas parótidas acessórias ao longo do ducto parotídeo (DI HIPÓLITO JUNIOR et al., 1997; DONE et al., 2002), fato observado neste estudo apenas no mão-pelada (Figura 1B).

$\mathrm{Na}$ face profunda da glândula parótida do quati e do mão-pelada foram encontrados diversos nódulos linfáticos, onde alguns estavam completamente cobertos por ela e outros apenas parcialmente cobertos, resultados este também encontrado nos gambás (Didelphis sp.) (MARTUCCI et al., 2004).

Microscopicamente a glândula parótida do quati e do mão- pelada é revestida por uma cápsula de tecido conjuntivo denso não modelado, que envia septos dividindo-a em lobos facilmente visíveis microscopicamente, assemelhando-se às descrições de Dyce et al. (2010), para os carnívoros domésticos. Nesses septos conjuntivos localizam-se vasos sanguíneos e linfáticos, nervos e ductos excretores, semelhantes às descrições de Banks (1991) e George et al. (1998).

No quati e no mão-pelada, os lobos da glândula parótida não são visíveis macroscopicamente como nos coelhos (GRECO et al., 2008), onde se apresentam de forma difusa, com uma cápsula frouxa, deixando os lóbulos evidentes e bem separados em sua superfície.

Os lóbulos da glândula parótida dos quatis e mãopeladas contêm tecido conjuntivo frouxo, onde estão localizados ductos que segundo a descrição de Poddar e Jacob (1977), Jacob e Poddar (1987) e Banks (1991) possuem enorme capacidade de armazenar e conduzir saliva.

Esses lóbulos nos quatis e mãos-peladas são repletos de ácinos serosos, que são característicos da 
FIGURA 1: Fotografia da face lateral esquerda do mão-pelada. 1A: glândula parótida (g.P); músculo masseter (m.M); músculo zigomático (m.Z); cartilagem auricular (c.A); ducto parotídeo (seta vazia); orelha (Or.). 1B: glândula parótida (g.P); glândula mandibular (g.M); músculo masseter (m.M); músculo zigomático (m.Z); cartilagem auricular (c.A); ducto parotídeo (seta vazia); glândula parótida acessória ao longo do ducto parotídeo (seta). Técnica de dissecação.
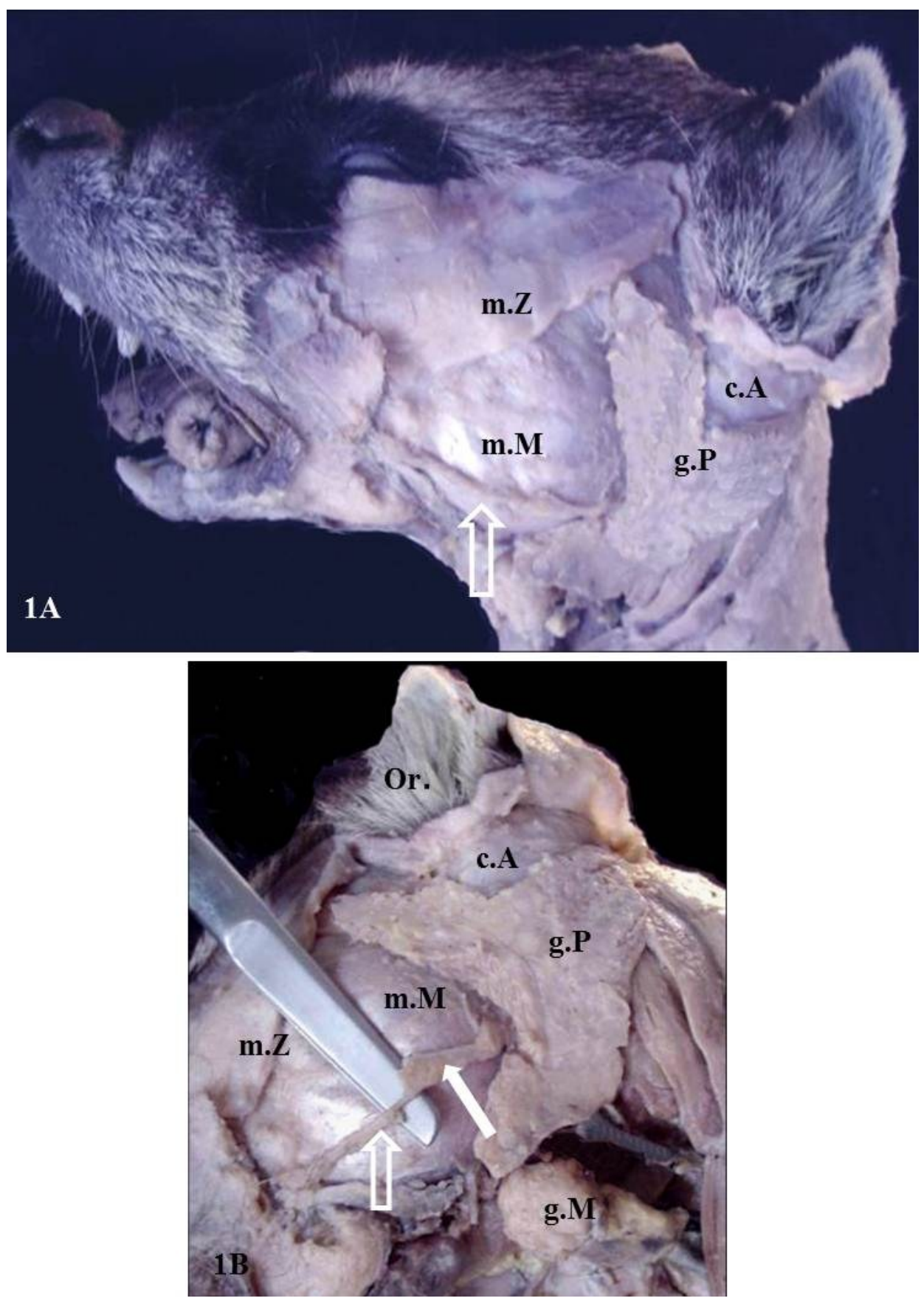
maioria das espécies domésticas e roedores adultos (TAKADA et al., 2001) além do homem (BANKS, 1991).

FIGURA 2: Fotografia da face lateral esquerda do quati. 2A: glândula parótida (g.P); glândula mandibular (g.M); músculo masseter (m.M); cartilagem auricular (c.A); ducto parotídeo (seta). 2B: glândula parótida (g.P); glândula mandibular (g.M); músculo masseter (m.M); cartilagem auricular (c.A); ducto parotídeo (seta). Técnica de dissecação.
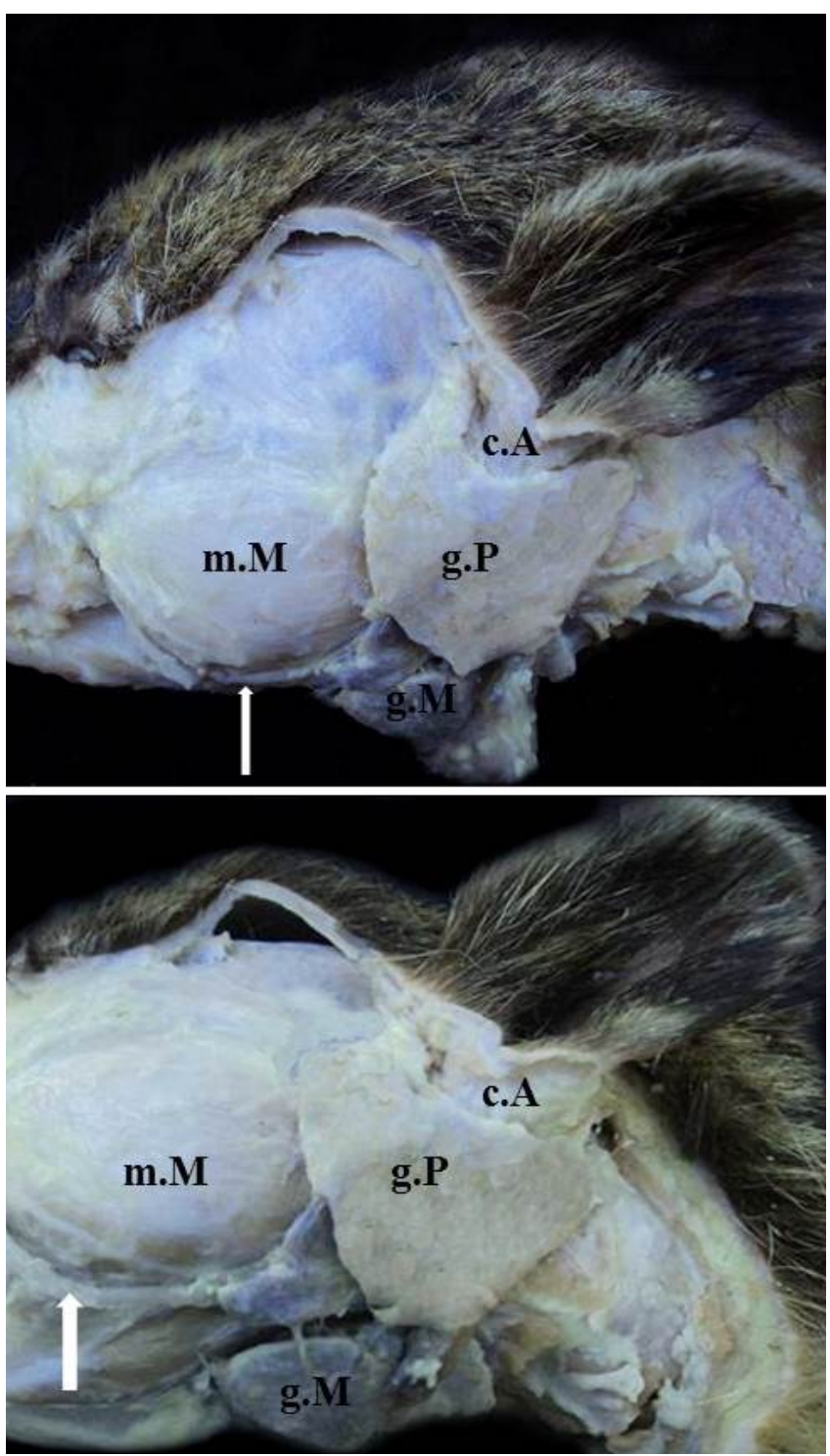

Dyce et al. (2010) relatam que a glândula parótida do cão e dos animais carnívoros possui células mucosas.

Nos furões a predominância é de ácinos mistos (serocomucosos) (PODDAR; JACOB, 1977; JACOB; PODDAR, 1987).
A secreção dos ácinos serosos dos quatis e mãospeladas desembocam em alvéolos, de onde são levados até os ductos intralobulares estriados (compostos por epitélio simples prismático) (Figuras 3B; 4A) pelos ductos intercalados, os quais são revestidos por epitélio cúbico simples que pode se tornar cúbico estratificado nas zonas de transição com os ductos interlobulares (Figuras 3E; 3F) onde estes se desembocam conforme a exemplo das descrições de Poddar e Jacob (1977), Jacob e Poddar (1987), Banks (1991) e Dyce et al. (2010) (Figuras 3C; 3D; 4B; 4D).

No entanto, no quati e no mão-pelada só foram encontrados ácinos puramente serosos (Figuras 3B; 4A; 4C).

Banks (1991), Stolte e Ito (1996) e George et al. (1998) descreveram que os ductos intralobulares estriados possuem células epiteliais que influenciam o conteúdo iônico e de água da secreção e que a superfície basal dessas células possui invaginações e interdigitações na membrana plasmática, que associadas a grande quantidade de mitocôndrias, servem para o movimento rápido de fluídos e íons que dão a característica estriada ao ducto.

Constatou-se neste trabalho que a glândula parótida dos quatis e mão-peladas possui posicionamento semelhante à dos demais carnívoros domésticos, com seus ductos se abrindo no vestíbulo oral, próximo à altura do quarto dente pré-molar superior, e que histologicamente é constituída por ácinos serosos, semelhante à da maioria dos animais domésticos, homens e roedores e diferentemente dos resultados encontrados nos cães jovens, cordeiros e alguns carnívoros como o furão (ácinos mistos) e de alguns carnívoros, que apresentam ácinos serosos e mucosos em sua constituição.

Conclui-se com este trabalho que o fato da constituição serosa dos ácinos das glândulas parótidas dos quatis e mão-peladas se assemelharem pode ser devido ao hábito alimentar onívoro compartilhado pelas duas espécies. 
FIGURA 3: Fotomicrografia de luz da glândula parótida do quati: 3A: cápsula de tecido conjuntivo denso não

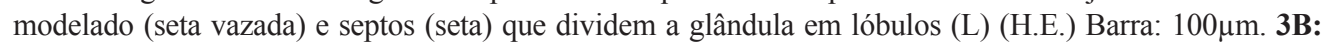
ducto intralobular estriado com epitélio simples prismático (seta) circundado por ácinos serosos (H.E.) Barra: $100 \mu \mathrm{m}$. 3C: ducto interlobular excretor (seta) com epitélio cúbico simples, e com epitélio cúbico

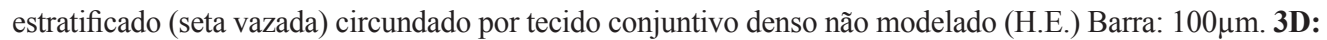
ductos interlobulares excretores com epitélio que varia de cúbico simples à estratificado (seta) (H.E.) Barra: $100 \mu \mathrm{m}$. 3E: ducto interlobular excretor com epitélio que varia de simples a estratificado em sua zona de transição com os ductos intralobulares intercalados (seta) (H.E) Barra: $200 \mu \mathrm{m}$. 3F: tecido conjuntivo denso não modelado circundando o ducto interlobular excretor (seta) (H.E.) Barra: $200 \mu \mathrm{m}$.
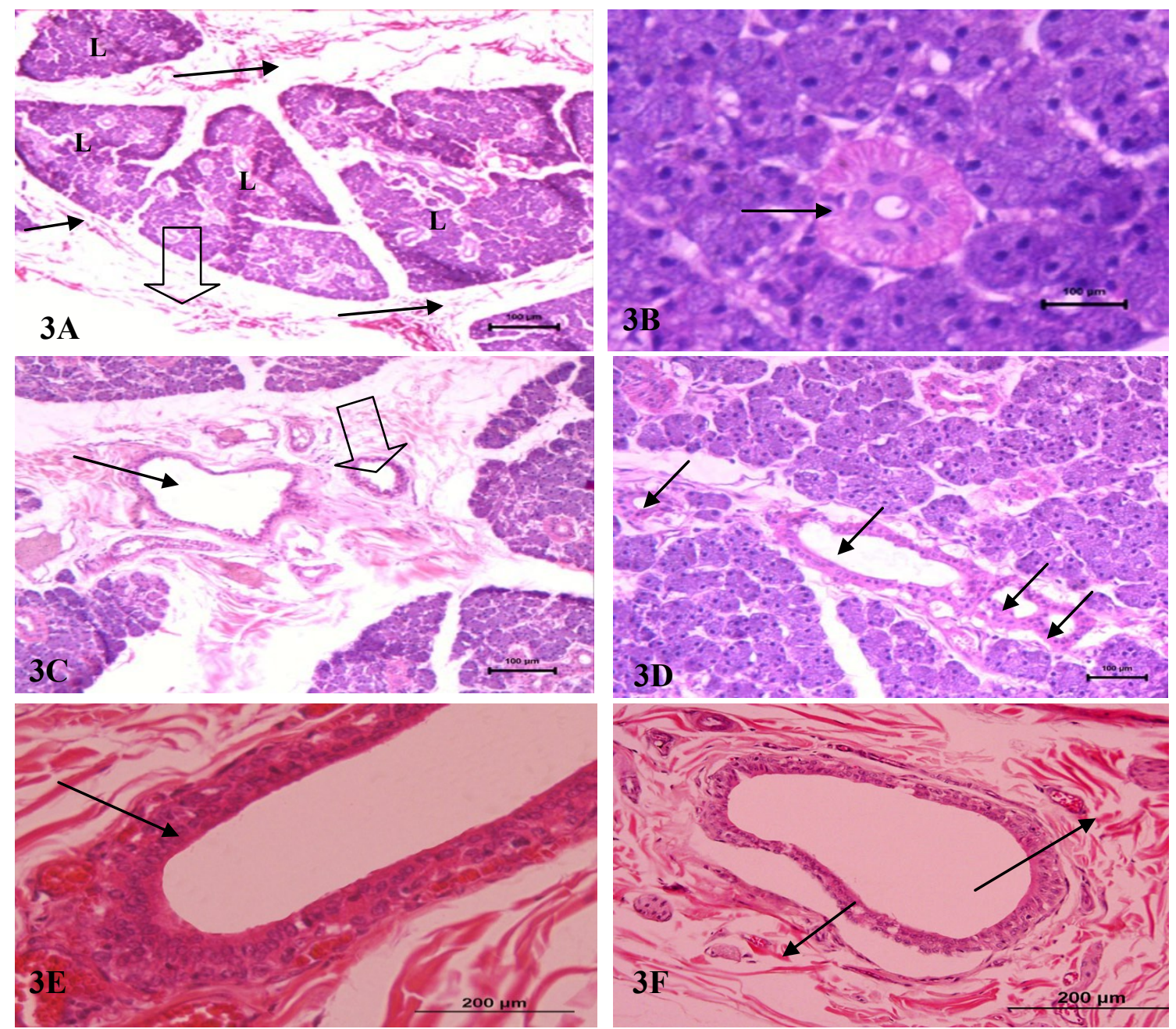
FIGURA 4: Fotomicrografia de luz da glândula parótida do mão-pelada. 4A: ducto intralobular estriado (seta vazada)

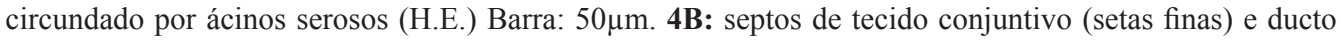

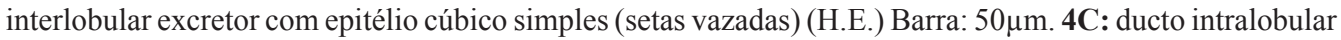

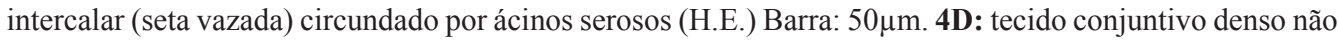
modelado (setas vazadas) circundando um ducto interlobular com epitélio que varia de cúbico simples a

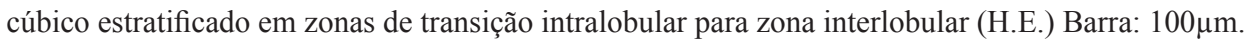
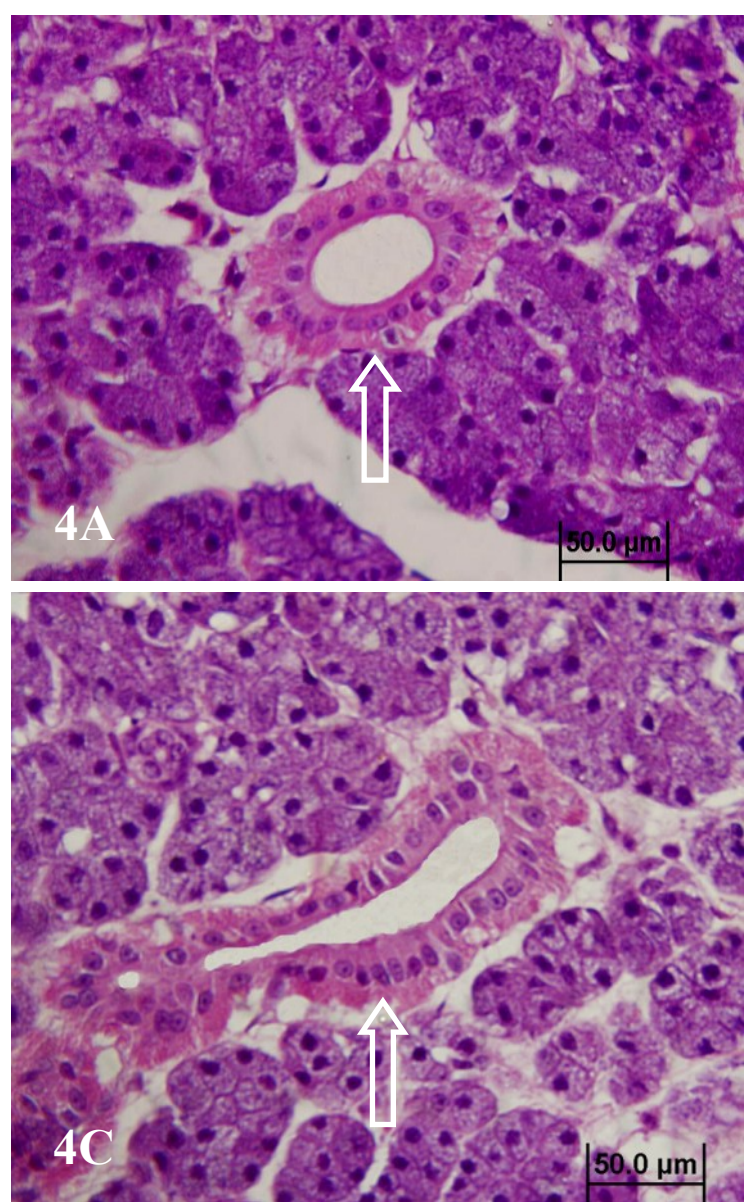
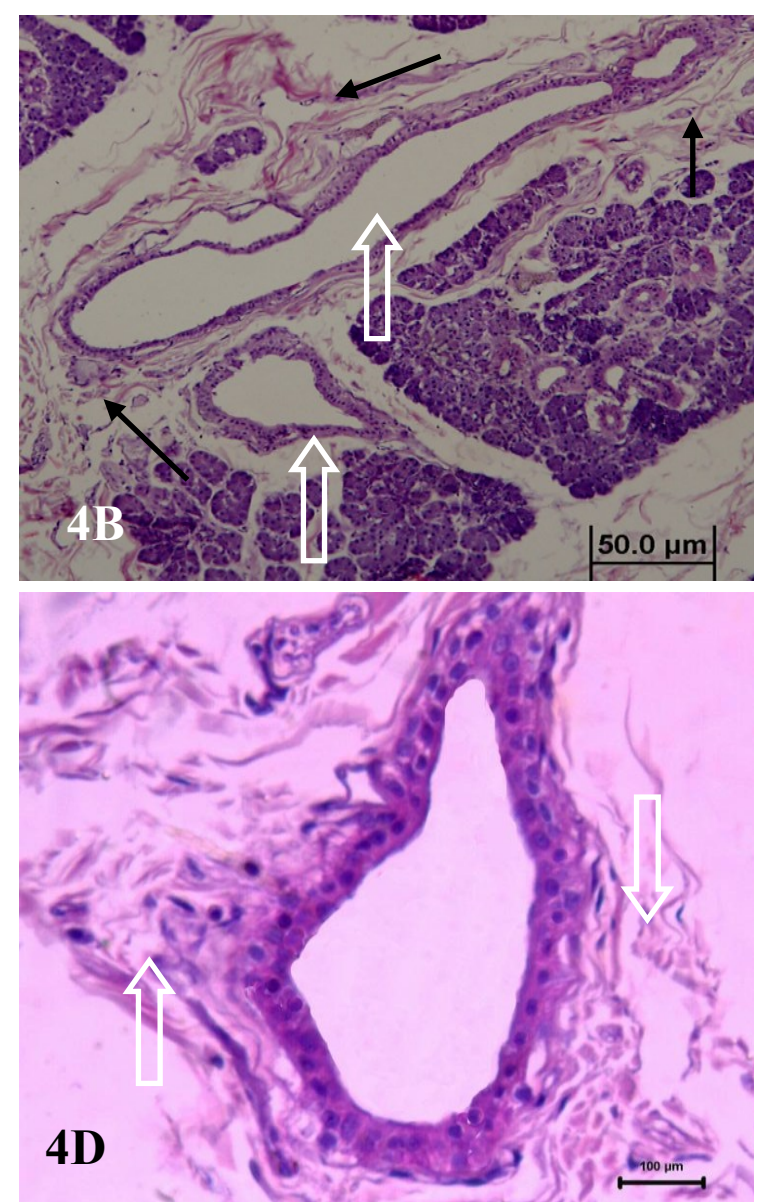

\section{Referências}

BANKS, W. J. Histologia veterinária aplicada. 2. ed. Manole: São Paulo, 1991. 654 p.

BEHMER, O. A. Manual de técnicas para histologia normal e patológica. Edart: São Paulo, 1976. 241 p.

BEISIEGEL, B. M. Notes on the coati, Nasua nasua (Carnívora: Procyonidae), in na Atlantic Forest area. Brazilian Journal of Biology, São Carlos, v. 6, n. 4, p. 689-692, 2001.

DI HIPOLITO JUNIOR, O.; KREICH, E. M .; HAITER NETO, F.; BOSCOLO, F. M. Sialografia de parótidas clinicamente normais: classificação anatômica e correlação com a função glandular. Revista de Odontologia Universidade de São Paulo, São Paulo, v. 11, n. 2, p. 139-145, 1997.

DONE, S, H.; GOODY, P. C.; EVANS, S. A.; STICKLAND, N. C. Atlas colorido de anatomia veterinária do cão e do gato. Manole: Barueri, 2002. 275 p.

DYCE, K. M.; SACK, W. O.; WENSING, C. J. G. Tratado de anatomia veterinária. 4 ed. Guanabara Koogan: Rio de Janeiro, 2010. $878 \mathrm{p}$.

ESTECONDO, S.; CODÓN, S. M.; CASANAVE, E. B. Histological study of the salivary glands in Zaedyus pichiy (Mammalia, Xenarthra, Dasypodidae). International Journal of Morphology, Temuco, v. 23, n. 1, p. 19-24, 2005.

GEORGE, L. L.; ALVES, C. E. R.; CASTRO, R. R. L. Histologia comparada. 2. ed. Roca: São Paulo, 1998. 298 p.

GRECO, M. G.; BAGETTI-FILHO, H. J. S.; BABINKI, M. A. CHAGAS, M. A.; SAMPAIO, M. A. P. Anatomia da glândula parótida em coelhos. Revista Brasileira de Medicina Veterinária, Rio de Janeiro, v. 30, n. 2, p. 129-131, 2008.

INTERNATIONAL COMMITEE ON VETERINARY GROSS ANATOMICAL NOMENCLATURE. Nomina Anatomica Veterinaria. 5. ed. Hannover, Columbia, Gent, Sapporo: Editorial Committee, 2005. 166 p. 
JACOB, S.; PODDAR, S. S. Ultrastructure of the ferret parotid gland. Journal of Anatomy, Maiden, v. 152, n. 1, p. 37-45, 1987.

LIMA, V. M.; PEREIRA, F. C.; PEREIRA, K. F. Estudo morfológico dos músculos do antebraço do mão-pelada, Procyon cancrivorus (Cuvier, 1798). Bioscience Journal, Uberlândia, v. 26, n. 1, p. 109114, 2010.

MARTUCCI, M.; MALEK, C.; AMBRÓSIO, C. E.; CARVALHO, A. F.; MIGLINO, M. A. Caracterização das glândulas salivares maiores do gambá (Didelphis sp.). ENCONTRO DE PRODUÇÃO ACADÊMICA, 5, 2004, São João da Boa Vista. Anais... São João da Boa Vista: Centro Universitário da Fundação de Ensino Octávio Bastos, 2004. p. 219.

MENDONÇA, C. S.; SILVA, F. O. C.; CUNHA, G. N.; COELHO, H. E. Topografia da papila parotídea em cães sem raça definida. Biotemas, Florianópolis, v. 17, n. 1, p. 217-224, 2004.

MOSCOVICI, M. Anatomia cirúrgica da porção terminal do nervo facial. Estudo do plexo bucal. Revista Brasileira de Neurologia, Rio de Janeiro, v. 45, n. 1, p. 43-50, 2009.

ORR, R. T. Biologia dos vertebrados. 5. ed. Roca: São Paulo, 1986. 508 p.

PODDAR, S.; JACOB, S. Gross and microscopic anatomy of the major salivary glands of the ferret. Acta Anatomica, Basel, v. 98, n. 4, p. 434-443, 1977.

SAMUELSON, D. A. Textbook of veterinary histology. Philadelphia: Saunders-Elsevier, 2007. 546 p.

SANTOS, A. C.; BERTASSOLI, B. M.; OLIVEIRA, V. C.; CARVALHO. A. F.; ROSA. R. A.; MANÇANARES, C. A. F. Morfologia dos músculos do ombro, braço e antebraço do quati (Nasua nasua, Linnaeus, 1758). Revista Biotemas, Florianópolis, v. 23, n. 3, p. 167-173, 2010a.
SANTOS, A. C.; BERTASSOLI, B. M.; OLIVEIRA, V. C.; ROSA. R. A.; CARVALHO. A. F.; MANÇANARES, C. A. F. Caracterização morfológica das glândulas salivares mandibulares dos quatis (Nasua nasua, Linnaeus, 1758). Revista da Faculdade de Zootecnia, Veterinária e Agronomia, Uruguaiana, v. 17, n. 2, p. 276-286, 2010b.

SANTOS, A. L. Q.; LIMA, E. M. M. Topografia das aberturas dos ductos parotídicos de um Lobo Guará (Chrysocyon brachyrus Illiger, 1811). Ciência Rural, Santa Maria, v. 31, n. 2, p. 333-335, 2001.

SCHALLER, O. Nomenclatura anatômica veterinária ilustrada. São Paulo: Manole, 1999. 614 p.

STOLTE M.; ITO, S. A comparative ultrastructural study of the parotid gland acinar cells of nine wild ruminant species (Mammalia, Artiodactyla). European Journal of Morphology, Londres, v. 34, n. 2, p. 79-85, 1996.

TAKADA, K.; AYAMA, S.; IKEDA, K. Morphological and histochemical changes in the secretory granules of mucous cells in the early postnatal mouse parotid gland. Archives of Histology and Cytology, Niigara, v. 64, n. 3, p. 259-266, 2001.

TOlOSA, E. M. C.; RODRIGUES, C. J.; BEHMER, O. A.; FREITAS NETO, A. G. Manual de técnicas para histologia normal e patológica. 2 ed. Manole: Barueri, 2003. 331 p.

VIEIRA, M. B. M.; PEREIRA, R. A.; SANTOS JR, N. B.; PINTO, R. V. Ressecção subcapsular da glândula submandibular. Revista Brasileira de Otorrinolaringologia, Rio de Janeiro, v. 67, n. 6, p. 825-828, 2001. 